\title{
Oral Administration of Bacillus subtilis Endospores Displaying Influenza Virus Matrix Protein 1 Elicit Cellular Immune Response in Mice
}

\author{
Tomasz Lęga ${ }^{1 *}$, Paulina Weiher ${ }^{2}$,Dawid Nidzworski² \\ ${ }^{1}$ Department of Medical Biotechnology, Intercollegiate Faculty of Biotechnology, University of Gdańsk and Medical University of Gdańsk, Dębinki 1, 80-211 \\ Gdańsk, Poland \\ ${ }^{2}$ Department of Recombinant Vaccine, Intercollegiate Faculty of Biotechnology, University of Gdańsk and Medical University of Gdańsk, Kładki 24, 80-822 \\ Gdańsk, Poland \\ ${ }^{3}$ Department of Recombinant Vaccine, Intercollegiate Faculty of Biotechnology, University of Gdańsk and Medical University of Gdańsk, Kładki 24, 80-822 \\ Gdańsk, Poland
}

Received: November 23, 2016; Accepted: December 20, 2016; Published: January 02, 2017

*Corresponding author: Tomasz Lega, Department of Medical Biotechnology, Intercollegiate Faculty of Biotechnology, University of Gdańsk and Medical University of Gdańsk, Dębinki 1, 80-211 Gdańsk, Poland, Tel: +48 58349 14 12; Fax: +48 58349 14 45; E-mail: tomasz.lega@biotech. ug.edu.pl

\begin{abstract}
Bacterium Bacillus subtilis is a gram-positive bacilli which produce endospores. Being metabolically dormant, spores are resistant to many environmental stressors such as UV radiation, desiccation, heat or freezing. There are evidence that oral or intranasal administration of spores presenting antigens induces a specific, both cellular and humoral immune response which can protect animals from infection. In our study, using a genetic approach we constructed Bacillus subtilis strains producing spores presenting influenza A virus matrix protein 1 (M1) on their surface. M1 protein was fused to spore coat CotZ protein and was stably exposed on the spore surface as demonstrated by the immunostaining of intact, recombinant spores. The immunogenicity of recombinant spores was tested by oral administration in mice. As proved by an IFN- $\gamma$ ELISPOT assay, constructed spores elicited significant cell-mediated immune response.
\end{abstract}

Keywords: Bacterial spores; Bacillus subtilis; Spore display; Influenza virus; Flu

\section{Introduction}

Development of an effective vaccine against infection influenza virus is a real challenge. A key problem for the development of effective vaccines against influenza is a high degree of antigenic variability of the virus strains circulating during the year. The constantly ongoing antigenic drifts and shifts of influenza virus cause the need for annual vaccination with a formulation against a specific strains circulating in a given season. Most existing vaccines are effective due to the ability to induce production of neutralizing antibodies directed against the capsular antigen-hemagglutinin [1]. Although the immunity which is based on antibodies is effective it is not universal and provides protection only against selected strains as a result of the antigenic variability of the virus. In contrast cellular-mediated immune response targets conserved antigens and can provide cross-immunity against different subtypes [2]. Influenza virusspecific Cytotoxic T Lymphocytes (CTLs) have been shown in animal studies to limit influenza A virus replication and to protect against lethal influenza A virus challenge [3]. In last year's a new live antigen carrier system emerged [4]. Recent studies show that recombinant endospores of Bacillus subtilis can serve as antigen carriers by fusing peptide of interest to spore coat proteins [5]. In our study we constructed Bacillus subtilis strain producing spores presenting influenza M1 protein on their surface. M1 is most abundant protein in influenza virons and it is conserved among various strains. Moreover it has been shown that vaccine based on M1 protein can elicit significant cellular response in vaccinated individuals [6]. Recombinant spores were orally administrated to mice to evaluate the immunogenic properties of constructs. This work indicates that spores can serve as influenza antigen carriers and induce cell-mediated immune response. Moreover co-administration of constructed spores with spores presenting interleukin 2 significantly boosted observed cellmediated response.

\section{Materials and Methods}

\section{Bacterial Strains and Transformation}

All strains used in this study are listed in Table 1. All cloning experiments were done using Escherichia coli DH5 $\alpha$ [7]. Bacteria were transformed according to the previously described methods: $\mathrm{CaCl}_{2}$-induced competence of E. coli cells [8] and transformation of B. subtilis [9].

\section{Construction of Recombinant Bacillus subtilis Strain}

To generate genetic fusion, gene cotZ coding for the coat protein was PCR-amplified together with its natural promoter using the $B$. subtilis 168 chromosomal DNA as a template and 
oligonucleotide pair cotZ-F/ cotZ-R listed in Table 2. Amplification product was digested with EcoRI and BamHI and cloned into the pDL vector [10] yielding plasmid pDL-CotZ.

DNA sequence coding for influenza A virus matrix protein 1),

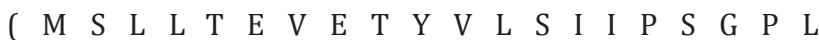
K A E I A Q R L E S V F A G K N T D LE A L M E W L K T R P ILGFVFTLTVPSERGLQRRRFVQNALNGNGDPNNMDRAVKLYKKLK REITFHGAKEVSLSYSTGALASCMGLIYNRMGTVTTEAAFGLVCATC EQIADSQHRSHRQMATTTNPLIRHENRMVLASTTAKAMEQMAGSS E Q A A E A M E VA N Q T R Q M V H A M R T I G T H P S S S A G L K DDLLENLQAYQKRMGVQMQRFK)

was synthesized (Life Technologies) with codon optimization for Bacillus subtilis and restriction site BamHI was added at the $5^{\prime}$ and SacI at the 3' end of the ORF. Synthesized fragment was digested with BamHI and SacI and cloned at the 3' end of the cotZ gene carried by pDL-CotZ obtaining plasmid pNC02.

Plasmid pNCO2 was linearized by digestion with a BsmBI restriction enzyme and used to transform B. subtilis 168. Transformation resulted in the integration of the plasmid into bacterial chromosome at the amyE locus in a double homologous recombination manner. Obtained Chloramphenicol-Resistant $\left(\mathrm{Cm}^{\mathrm{R}}\right)$ clones were PCR-tested for the incorporation of the fusion gene at the amyE locus in B. subtilis 168 chromosome using oligonucleotide pair AmyS/AmyA Table 2. Selected clone was called BNC02 [Table 1]

\section{Production of Spores}

Sporulation was induced using the previously described

\begin{tabular}{|c|c|c|}
\hline Strain & Relevant genotype & $\begin{array}{l}\text { Source or } \\
\text { reference }\end{array}$ \\
\hline \multicolumn{3}{|c|}{ Bacillus subtilis } \\
\hline 168 & $\operatorname{trpC2}$ & [17] \\
\hline BNC02 & amyE::cotZ-M1 & This work \\
\hline BKH121 & amyE::cotB- GGGEAAAKGGG-IL-2 & [18] \\
\hline \multicolumn{3}{|c|}{ Escherichia coli } \\
\hline BL21(DE3) & $\begin{array}{c}\text { fhuA2 [lon] ompT gal ( } \lambda \text { DE3) [dcm] } \\
\Delta \text { hsdS } \lambda \text { DE3 }=\lambda \text { sBamHIo } \Delta \text { EcoRI-B } \\
\text { int::(lacI::PlacUV5::T7 gene1) i2 } 1 \\
\Delta \text { nin5 }\end{array}$ & NEB Inc., USA \\
\hline DH5 $\alpha$ & $\begin{array}{l}\text { fhuA2 lac(del)U169 phoA glnV44 } \\
\Phi 80 \text { ' lacZ(del)M15 gyrA96 recA1 } \\
\text { relA1 endA1 thi-1 hsdR17 }\end{array}$ & [7] \\
\hline
\end{tabular}

Table 2: List of the PCR Oligonucleotides

\begin{tabular}{|l|l|l|}
\hline Name & Sequence & Restriction site \\
\hline cotZ-F & GCTTAGGATCCATGATGATGTGTACGATTG & BamHI \\
\hline cotZ-R & $\begin{array}{l}\text { CGTAGCGAATTCAGTTATCACTCTTGT } \\
\text { CCTC }\end{array}$ & EcoRI \\
\hline AmyS & CCAATGAGGTTAAGAGTATTCC & - \\
\hline AmyA & CGAGAAGCTATCACCGCCCAGC & - \\
\hline
\end{tabular}

nutrient depletion method in Difco Sporulation Medium (DSM) [11]. Briefly, 48-hour bacterial cultures were harvested and washed in $1 \mathrm{M} \mathrm{KCl}$, treated with lysozyme followed by washing steps in $1 \mathrm{M} \mathrm{NaCl}, 0.05 \%$ (w/v) Sodium Dodecyl Sulfate (SDS) and water. The purified spores were titrated using Thoma chamber and stored at $-20^{\circ} \mathrm{C}$.

\section{Western Blotting Analyses}

To extract spore coat proteins a buffer containing $0.1 \mathrm{M}$ $\mathrm{NaCl}, 0.1 \mathrm{M} \mathrm{NaOH}, 0.1 \mathrm{M}$ Dithiothreitol (DTT) and 1\% (w/ v) SDS was used. $5 \times 10^{8}$ spores were resuspended in $50 \mu \mathrm{L}$ of decoating buffer and incubated for $30 \mathrm{~min}$ at $70^{\circ} \mathrm{C}$ with shaking (1000 rpm). Suspension was centrifuged (10 $000 \mathrm{RCF}, 10 \mathrm{~min}$, RT) and supernatant kept for further analysis. Extracted spore coat proteins were separated in NuPAGE ${ }^{\circledR}$ Novex® ${ }^{\circledR} 4-12 \%$ Bis-Tris pre-cast polyacrylamide gels (Life Technologies), electrotransferred on a nitrocellulose using iBlot ${ }^{\circledR} 2$ Dry Blotting System (Life Technologies). Membranes were incubated overnight at $4^{\circ} \mathrm{C}$ with GA2B anti-influenza A matrix protein $1 \mathrm{Mab}$ (Pierce). Western blots were visualized developing with BCIP/ NBT according to the manufacturer's instructions (Thermo Scientific).

\section{Immunofluorescence Microscopy}

Samples were fixed directly in the medium as described by Negri A, et al. [12]. Briefly, intact spores were incubated overnight at $4^{\circ} \mathrm{C}$ with GA2B anti-influenza A matrix protein $1 \mathrm{mAb}$ (Pierce), followed by incubation with anti-mouse Cy3 (Jackson Immuno Research) overnight at $4^{\circ} \mathrm{C}$. Samples were loaded on microscope slides and viewed using a Zeiss Axioplan fluorescence microscope.

OBALB/c mice were purchased from the breeding facilities at the Medical University of Gdańsk. The animals were kept in polycarbonate cage, housed in well aerated rooms with a 12-h light/12-h dark cycle at $25 \pm 2^{\circ} \mathrm{C}$, fed with normal pellet diet and water ad libitum. The physical condition of the animals was monitored daily. None of the animals exhibited clinical signs indicative of severe illness during experiment and $100 \%$ of mice reached humane endpoint euthanasia which was performed by carbon dioxide inhalation followed by cervical dislocation.

Three groups of five mice (female, 8 weeks) were immunized using intragastric gavage with water suspension of recombinant spores expressing CotZ-M1 (BNC02), mixture of CotZ-M1 (BNC02) CotB-IL-2 (BKH121) fusions or control, non-recombinant spores (strain 168). Oral immunizations contained $1.0 \times 10^{10}$ spores in a volume of $0.2 \mathrm{ml}$ in case of spores BNC02 and 168 or contained 1:1 ratio of $0.5 \times 10^{10}$ spores in a volume of $0.2 \mathrm{ml}$ in case of mixture of BNC02 and BKH121 and were administered by oral gavages on days $1,3,5,22,24,26,43,45,47$. Spleens were collected from all of the animals on day 61 .

\section{IFN- $\gamma$ ELISpot Assay}

Spleens were isolated and single cell suspension was prepared as described elsewhere [13].

The number of IFN- $\gamma$-secreting cells was determined by using mouse IFN- $\gamma$ ELISpot kit according to manufacturer's instructions 
(BD ELISpot). Splenocytes $\left(1 \times 10^{5}\right)$ were cultured for $48 \mathrm{~h}$ in presence of recombinant M1 antigen previously described [14]. The spots were counted using automated ELISpot plate reader (CTL-ImmunoSpot S6 Micro Analyzer, USA).

\section{Statistics}

ELISpot tests have been performed for each animal in three technical repeats. Statistical significance of the data was determined by one-way analysis of variance followed by the Bonferroni posttest.

\section{Results and Discussion}

\section{Spore Coat Expression and Surface Display of M1 Antigen}

The presence of fusion protein in the recombinant endospore coat was tested by western blotting with mouse monoclonal antiinfluenza A M1 antibodies (Pierce). As demonstrated by western blotting [Figure 1A]. CotZ-M1 fusion protein was expressed and located in the spore coat. However, observed molecular weight (35 kDa) of the fusion protein differ from the calculated (45 kDa). This could be due to the reported previously instability of the M1 protein in the bacterial expression systems $[15,16]$. In our work M1 protein was fused to the C-terminus of spore coat CotZ protein. It has been shown that M1 C-terminal domain (residues 165 to 252) is quite susceptible to degradation by endogenous bacterial proteases. This falls with our observation as the residues 165 to 252 is $10 \mathrm{kDa}$. The surface exposition of fusion protein was analyzed by immunofluorescence microscopy of dormant spores of wild type and recombinant strains using mouse monoclonal (GA2B) anti-influenza A M1 antibodies (Pierce) as primary antibodies and anti-mouse IgG-Cy3 (Jackson Immuno Research) as secondary antibodies. We observed a specific, fluorescent signal only from recombinant spores [Figure 1B].

\section{Immune Response to Recombinant Spores}

To asses immunogenic properties of constructs and whether spores presenting IL-2 will act as an adjuvant we immunized
A

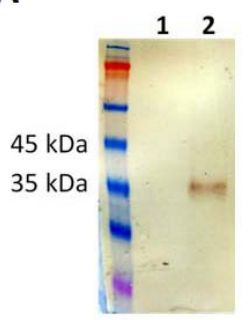

B

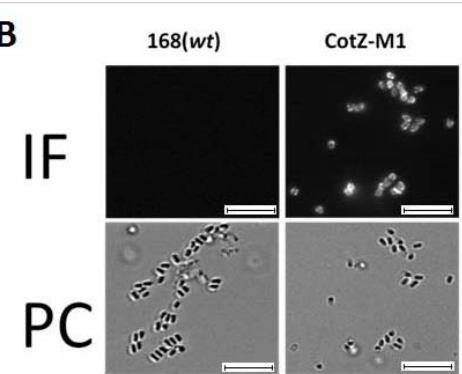

Figure 1: (A) Western blot analysis of expression of fusion gene. Spore coat proteins were extracted and analyzed by western blotting with anti-influenza M1 mAb. . Numbers of lanes refer to the strain used in experiment: 1-B. subtilis 168; 2-BNC02(CotZ-M1, 35kDa). (B) Immunofluorescence staining of recombinant spores. Purified spores were incubated with anti-influenza M1 mAb, followed by anti-mouse Cy3 conjugates. Spores were visualized by phase contrast (PC) and immunofluorescence (IF) microscopy. The same exposure time was used for all IF images. Scale bar $10 \mu \mathrm{m}$.

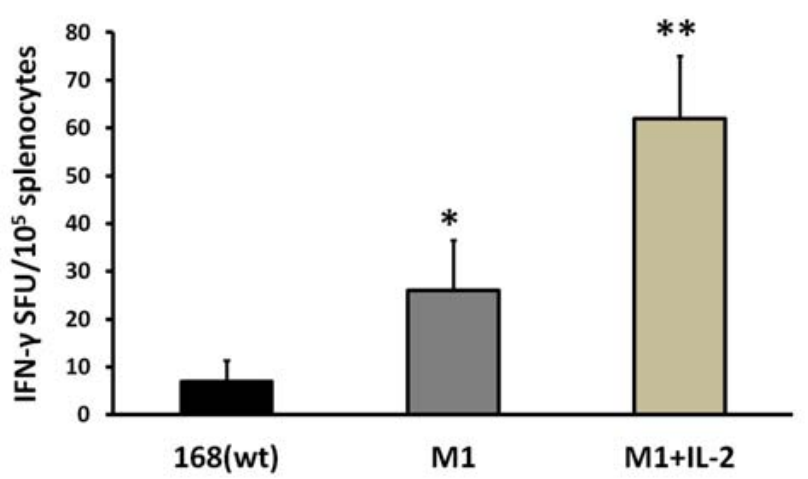

Figure 2: IFN- $\gamma$ response of sensitized mouse splenocytes to M1 as assessed by the ELISpot. The splenocytes were isolated from mice orally immunized with 168 spores (black closed bar), BNC02 (CotZ-M1) (grey closed bar) or 1:1 mixture of BNC02 and BKH121(CotB-IL-2) (light-gray closed bar). Cells were incubated with purified M1 protein for $48 \mathrm{~h}$ and then the IFN- $\gamma$-secreting cells were enumerated by ELISpot procedure. Error bars represent standard deviation. ${ }^{*} p$-value $<0.05$, ** $p$-value $<$ 0.01 against $168(w t)$.

orally mice either with spores presenting M1 antigen (BNC02), mixture of spores presenting M1 antigen and interleukin 2 (BNC02+BKH121) or non-recombinant spores (168). To test induction of cellular immune response we conducted IFN- $\gamma$ ELISpot using splenocytes from immunized mice. A significant increase in the number of IFN- $\gamma$-secreting cells stimulated with recombinant M1 was observed in case of mice immunized with BNC02 spores [Figure 2]. These results suggest the induction of specific cell-mediated immune response. Moreover, when co-administered with BHK121, spores presenting M1 protein increased the strength of observed immune response. The key question is whether observed response would provide a robust therapeutic or protective immunity? In our opinion spores constructed in this research rather have the potential to serve as a specific immunostimulant adjunctive the standard immunization procedures than as a standalone oral vaccine.

In summary, the system presented in this work seems to be a promising candidate as a formulation stimulating the immune system to fight the infection with influenza virus. Although coadministration of IL-2 presenting spores as an adjuvant increases the efficiency of immunization, further research is required to assess protective and therapeutic potentials of such formulation.

\section{Acknowledgements}

The research was supported by the Polish National Center for Research and Development grant no LIDER/016/489/L-4/12/ NCBR/2013.

Project supported by to Foundation for Polish Science (FNP).

We express our thanks to prof. Boguslaw Szewczyk and prof. Michal Obuchowski for their advices and encouragement during realization of this project. 


\section{Conflict of Interests}

The authors declare that they have no conflict of interests.

\section{Ethical Approval}

The animal procedures protocol was approved by the Committee on the Ethics of Animal Experiments of the Medical University of Gdańsk (Permit Number: 3/2014).

\section{Reference}

1. Lee YT, Kim KH, Ko EJ, Lee YN, Kim MC, Kwon YM, et al. New vaccines against influenza virus. Clin Exp Vaccine Res. 2014;3(1):12-28. doi: 10.7774/cevr.2014.3.1.12.

2. Nguyen HH, Moldoveanu Z, Novak MJ, van Ginkel FW, Ban E, Kiyono $\mathrm{H}$, et al.. Heterosubtypic immunity to lethal influenza A virus infection is associated with virus-specific CD8(+) cytotoxic T lymphocyte responses induced in mucosa-associated tissues. Virology. 1999;254(1):50-60.

3. Hemann EA, Kang SM, Legge KL. Protective CD8 T cell-mediated immunity against influenza A virus infection following influenza virus-like particle vaccination. J Immunol. 2013;191(5):2486-94. doi: 10.4049/jimmunol.1300954.

4. Amuguni H, Tzipori S. Bacillus subtilis: a temperature resistant and needle free delivery system of immunogens. Hum Vaccin Immunother. 2012;8(7):979-86. doi: 10.4161/hv.20694.

5. Iwanicki A, Piątek I, Stasiłojć M, Grela A, Lęga T, Obuchowski M, et al. A system of vectors for Bacillus subtilis spore surface display. Microb Cell Fact. 2014;13(1):30. doi: 10.1186/1475-2859-13-30.

6. Lillie PJ, Berthoud TK, Powell TJ, Lambe T, Mullarkey C, Spencer AJ, et al. Preliminary assessment of the efficacy of a T-cell-based influenza vaccine, MVA-NP+M1, in humans. Clin Infect Dis. 2012;55(1):19-25. doi: $10.1093 / \mathrm{cid} / \mathrm{cis} 327$

7. Woodcock DM, Crowther PJ, Doherty J, Jefferson S, DeCruz E, NoyerWeidner M, et al. Quantitative evaluation of Escherichia coli host strains for tolerance to cytosine methylation in plasmid and phage recombinants. Nucleic Acids Res. 1989;17(9):3469-78.

8. Green MR, Sambrook J. Molecular cloning. A laboratory manual. Cold Spring Harbor Laboratory Press. Cold Spring Harbor. 2012.
9. Julkowska D, Obuchowski M, Holland IB, Séror SJ. Comparative analysis of the development of swarming communities of Bacillus subtilis 168 and a natural wild type: critical effects of surfactin and the composition of the medium. J Bacteriol. 2005;187(1):65-76.

10.Yuan G, Wong SL. Regulation of groE expression in Bacillus subtilis: the involvement of the sigma A-like promoter and the roles of the inverted repeat sequence (CIRCE). J Bacteriol. 1995;177(19):5427-33.

11. Nicholson, W. L., and P. Setlow. 1990. Sporulation, germination and outgrowth, p. 391-450. In C. R. Harwood and S. M. Cutting (ed.). Molecular biological methods for Bacillus. John Wiley \& Sons Ltd., Chichester, England.

12. Negri A, Potocki W, Iwanicki A, Obuchowski M, Hinc K. Expression and display of Clostridium difficile protein FliD on the surface of Bacillus subtilis spores. J Med Microbiol. 2013;62(Pt 9):1379-85. doi: 10.1099/ jmm.0.057372-0.

13. Stasiłojć M, Hinc K, Peszyńska-Sularz G, Obuchowski M, Iwanicki A. Recombinant Bacillus subtilis Spores Elicit Th1/Th17-Polarized Immune Response in a Murine Model of Helicobacter pylori Vaccination. Mol Biotechnol. 2015;57(8):685-91. doi: 10.1007/ s12033-015-9859-0.

14. Nidzworski D, Pranszke P, Grudniewska M, Król E, Gromadzka B. Universal biosensor for detection of influenza virus. Biosens Bioelectron. 2014;59:239-42. doi: 10.1016/j.bios.2014.03.050.

15. Burleigh M, Calder J, Skehel J, Steinhauer D. Influenza A Viruses with Mutations in the M1 Helix Six Domain Display a Wide Variety of Morphological Phenotypes. J Virol. 2005;79(2): 1262-1270.

16. Noton S, MedcalfE, Fisher D, Mullin A, Elton D, Digard P. Identification of the domains of the influenza A virus M1 matrix protein required for NP binding, oligomerization and incorporation into virions. J Gen Virol. 2007;88(Pt 8):2280-90.

17. Anagnostopoulos C, Crawford IP. Transformation studies on the linkage of markers in the tryptophan pathway in Bacillus subtilis. Proc Natl Acad Sci U S A. 1961;47:378-90.

18. Hinc K, Stasiłojć M, Piątek I, Peszyńska-Sularz G, Isticato R, Ricca E, et al. Mucosal adjuvant activity of IL-2 presenting spores of bacillus subtilis in a murine model of Helicobacter pylori vaccination. PLoS One. 2014;9(4):e95187. doi: 10.1371/journal.pone.0095187. 